\title{
CIRCULAR ECONOMY ADOPTION WITHIN 3D PRINTING INDUSTRY: THE STATE OF THE ART, MAJOR ISSUES AND CHALLENGES
}

\author{
Angelina Rayside ${ }^{1}$, Boppana Chowdary ${ }^{2 *}$ and Prasanta Dey ${ }^{3}$ \\ 1,2Faculty of Engineering, The University of the West Indies, Trinidad \\ 3Aston Business School, Aston University, UK \\ 1Email: angelina.rayside@my.uwi.edu \\ 2Email: boppana.chowdary@sta.uwi.edu* (Corresponding author) \\ 3Email: p.k.dey@aston.ac.uk
}

\begin{abstract}
There is a growing realisation in the international community that economic development and environmental conservation must achieve a balance to enable future generations to survive and prosper as we exist on a planet of finite resources. Circular Economy (CE) has emerged as a paradigm shift to assist in attaining this balance. It has been argued that industry can achieve CE through five phases - take, make, distribute, use and recover i.e. converting their linear business processes (take, make and distribute) to circular. 3D printing/Additive Manufacturing (AM) industry is developing speedily and it could potentially involve trillions of dollars in business over the coming decades. 3D printing inadvertently achieves some of the most urgent environmental and resource goals facing the global industry. For example, the transportation and manufacturing carbon footprint of many products could be reduced as design, rather than products, is shipped. Further, 3D Printers will manufacture personalized products locally and only on demand. Moreover, with developments in bio-based 'smart' materials, the 3D printing process itself can lead to significant material savings. The promise of 3D printing with bio-materials is that it can create a fully sustainable and circular manufacturing process. The literature indicates that the 3D printing industry can contribute various parts of the circular economy system: especially in maintenance, re-use, re-manufacturing and re-cycling of products and goods. Though there is evidence in other manufacturing processes, literature on 3D printing industry adoption of $\mathrm{CE}$ is scanty. As the $3 \mathrm{D}$ printing industry has the promise to become the clear winner in realising a sustainable $\mathrm{CE}$, the main objective of this paper is to identify the major issues and challenges of each phase of CE. The outcome of the study gives the way forward to the most urgent environmental and resource constraints facing the product suppliers scattered around the globe.
\end{abstract}

Keywords: 3D printing, Additive manufacturing, Circular economy, Re-cycling, Remanufacturing

https://doi.org/10.47412/EZCQ1118

\section{Introduction}

Circular Economy (CE) is a profound ideology that goes beyond the 'reduce, reuse, recycle' movement that is yet to pervade many industries. While international efforts continue to campaign the importance of environmental stability, landfills around the world are continually dumped with tons of solid waste. Since 
the industrial revolution, the global manufacturing sector had operated as a linear economy: resources are extracted, a product is created then the product is discarded. However, Circular Economy involves the complete eradication of industrial waste - beginning at the product design stage - therefore keeping manufactured products in use within the economy. CE has the potential to revolutionize the manufacturing and production sectors of today, which is currently rapidly inundated by the 3D printing industry. 3D printing - also known as additive manufacturing - has become the primer cost-effective method of mass production, rewarding businesses with reduced product development periods, lessened costs for manufacturing start-up and profitable returns on investment.

Additive manufacturing eliminates the generation of material waste by 'printing' parts in successive layers, thereby achieving high levels of design complexity that is difficult - and in some cases impossible - with traditional manufacturing processes. Costs and energy usage in transportation, shipping, handling and storage of raw materials and work-in-progress parts are drastically reduced. The integration therefore of 3D printing with Circular Economy further pushes the elimination of material waste and its subsequent issues, and re-integrates spent products back into use. Bio-materials would allow manufactured products to safely break down into natural elements, and also be re-manufactured without much reduction in physical properties or quality. The promises of these however, are not without its challenges, especially at the technical and organizational levels, which require industrial and sectorial collaboration. Concerning the progression of Circular Economy integration within the 3D printing industry, there exists little systematic literature analysis on the topic.

The 2018 Circularity Gap Report developed by the Circle Economy Organization reads that $9.1 \%$ of the world was operating under circular practices, leaving a massive circularity gap of $89.9 \%$ [1]. The report, which was the first of its kind, sought to track the progress of the gap's closure through a global circularity metric. However, the 2019 Circularity Gap Report revealed that the world is now operating at 9\%, stating that "in terms of sustainability and circularity, the global engine of change is stuck in reverse; we are still heading in the wrong direction" [2]. Documentation is therefore needed to help understand the hindrance of the progress of circularity in the world's systems, beginning with its relationship with the 3D printing empire. The aim of this paper is to discern the state of the art of this CE adoption, and to determine the issues that have arisen through this integration. The main body of the paper would seek to answer two research questions as the basis of the study. The methodology employed in this research is to gather academic literature from past works from different industries and experts in the field. For each research question postulated, a detailed discussion would be untaken to address the structure and outcome of the research, and also to determine any research gaps. At the culmination of this study, a clearer picture of the progress of circular economy with 3D-printing technology will be determined, as well as the way forward.

\section{Research Aim}

The aim of the research is to understand the state of the progression of circular economy within the 3D printing or additive manufacturing sector. This integration has arisen out of the need for the manufacturing industry to become more sustainable, as the influx of production waste threatens to negatively impact the environment in the long-term. Even though both additive manufacturing and circular economy have been in development within the last fifty years, limited research has been done into their collaboration. The hope is to achieve a sense of understanding as to the extent to which the integration has been successful, and to determine the gaps in prior research conducted. It is imperative to comprehend and acknowledge the direction in which the industry is heading, therefore this study was chosen to establish familiarity with the topic as it gains traction and gradually propagates into a socio-economic and cultural shift. This paper would seek to investigate the state of the art of this integration through following research questions:

1. How does $3 \mathrm{D}$ printing facilitate $\mathrm{CE}$ adoption and is there any established framework?

2. What are the major challenges that inhibit the progression of CE in the additive manufacturing industry? 


\section{Research Methodology}

\subsection{Creation of Research Database}

In order to attain information on the $\mathrm{CE} / 3 \mathrm{D}$ printing integration from credible sources, information was first collected from other research papers that directly dealt with the topic of integration. Key search terms such as '3D printing', 'Circular Economy' and 'Integration' were utilized for the retrieval of papers from journals and other reputable online sources. After this initial stage, the research scope was then broadened to those that dealt with either the impact of 3D printing sector or the rise of the Circular Economy. A database was then created, which stored information such as title, year of publication and author(s).

\subsection{Literature Analysis}

In-depth investigation on the research was conducted to determine the association of 3D printing and circular economy, and any common themes and issues were presented. Each source was read through, and any correlations were noted. The information gathered was then divided into two categories: one for each of the postulated research questions. Any framework or facilitation methods were presented and discussed.

\subsection{Challenges}

Upon the investigation, the various challenges and issues associated with the concepts of 3D printing, circular economy and their integration were compiled. This compilation was further assessed by subdividing it into categories. These categories were determined through the nature of the issues discovered. All relevant research concerning the state of the art of the integration and their challenges faced was then presented and discussed.

\section{Literature Review}

Circular economy (CE) is a paradigm shift from the linear and recycled economies, closing the loop that has led to the majority of production waste being discarded beyond retrieval. This idea of 'circularity' has emerged to re-evaluate how we use resources not only for production and economic systems, but also to tackle resource scarcity as human population and its demands increase [3]. The relationship between CE and sustainability has not been made explicit in literature and has therefore constrained the efficacy of using the approaches in research and practice [4]. Within the last decade, a modest number of studies have been conducted on circular economy and its relationship with additive manufacturing and other aspects of the production sector. Those that did not directly address CE and 3D hinted to the concept of regenerative production by publishing under relevant broader terms such as 're-distributed manufacturing', 'sustainable production', 'cradle-to-cradle production', 'sustainable supply chains', 'circular product design' and 'closed-loop manufacturing system'. One immediate issue discovered was the fluidity of definition of sustainability, causing a plethora of contradictory and confusing definitions that demonstrate a general lack of understanding [5].

Other articles conducted literature analyses of the integration such as the conference paper by Betim et al. (2018). In this publication, nine research articles were compiled and it was found that recycling, remanufacturing, biomaterials and design were the main research areas. The study concluded that these new manufacturing routes should be driven towards stability through established standards and that any new research should be based on the entire product life cycle [6]. Another literature analysis done by Sauerwein, Bakker \& Balkenende (2017) outlined the aspects of additive manufacturing that could result in possibilities for sustainability, such as design for customization, absence of specialized tooling and local production [7]. These aspects were then mapped to the circular design strategies postulated by Bakker et al (2014) using 
five design project examples. Unlike Betim et al (2018), the authors were able to determine correlations between 3D printing and circular economy through practical examples. Diegal et al (2016) identified circular economy as a sustainable design approach, and 3D printing as a means to positively contribute to sustainable development. The article identified new sustainability challenges associated with additive manufacturing and states that "the field of product design needs to evolve in parallel so as to meet better the demands of emerging sustainable design trends" [5].

Concerns were raised in the research done by Giurco et al (2014) with respect to minerals responsibility and material recyclability in a world which aims for circular economy and futuristic manufacturing trends. The study concludes by asserting that additive manufacturing had the potential to reduce material throughput and extend product lifetimes, but without ensuring design for disassembly overall results may be mixed [8]. Throughout the literature surrounding 3D printing and circular economy, concerns such as lack of definition and standardization, experimental approaches which would be difficult to implement on a large scale, already established policies that have been optimized for particular organizations [9] and lack of thorough research in the impact of such a transition have been brought up by many researchers. Whilst numerous individual players are attempting to churn their operations in the circular direction, it is observed that in order for the impact of circular economy to become the norm, it must arise through the efforts of entrepreneurial start-ups, rather than by transforming existing organizations [9]. Many other challenges and potential challenges were raised across the literature and would be further evaluated in Section 4.2. These issues were not addressed as isolated sections in their respective articles, but were rather closely mentioned with the potentials of circular manufacturing and 3D printing technology. This is a testament to the degree of resistance and lack of comprehensibility of the integration, and attests therefore to the need of more research into the topic.

\section{Research Questions}

\subsection{Question 1 - How does 3D printing facilitate CE adoption, and is there any established framework?}

Additive manufacturing technology and circular economy are both just beginning to be standardized in the global manufacturing sector and are both viable strategic approaches in the quest for sustainability. This is an issue that both designers and engineers must engage with and embrace to survive in a more sustainability conscious world [5]. In order for manufacturing companies to remain competitive, profitable and commercially relevant, they must demonstrate a commitment to environmental responsibility and sustainability within their operations. The Ellen MacArthur Foundation postulates that the first principle for achieving a circular economy is to design out waste and pollution by viewing waste as a design flaw [10]. Products should be designed to last, to be repairable, and at the end of its lifecycle to be broken down so that each part of it finds another use [11]. This process must begin at the product design stage. Rapid prototyping is a design practice which accelerates the design process while reducing product start-up time, and is frequently utilized with $3 \mathrm{D}$ printing. Additive manufacturing therefore allows designers to conduct rapid iterations of designs to eradicate the aspects of their product that would be traditionally considered waste. Manufacturing strategies must also be developed to implement the technical characteristics of modularity, disassembly and repair-friendly features into products [12]. The following chart was derived from the study done by Sauerwein, Bakker \& Balkenende (2017) revealing correlations between circular design strategies and sustainable aspects of additive manufacturing [7]. The blue circles represent the circular strategies and the arrows are their corresponding additive manufacturing aspects. 


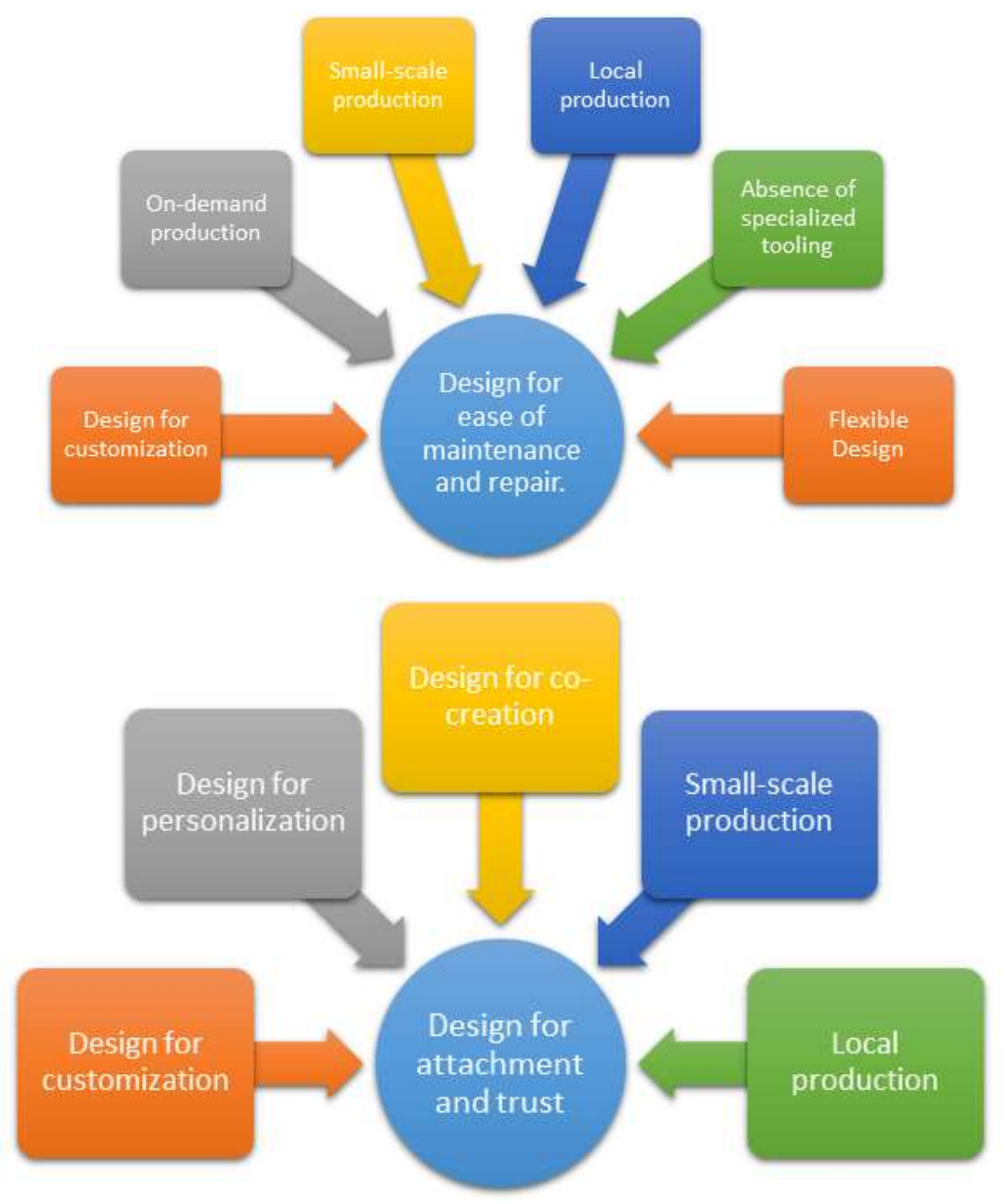

Figure 1: Comparison of Circular Design Strategies and Sustainable Aspects of AM

(Derived from Sauerwein, Bakker \& Balkenende (2017))

The study revealed some strong linkages, for example, on-demand production and local production (3D printing attributes) facilitate design for ease of maintenance and repair and design for upgradability (circular economy characteristics). Design for recyclability was facilitated by the local production and flexible design aspects of additive manufacturing. Subsequent similar studies with a larger number of design projects would yield even more linkages that would further cement 3D printing technology as an enabler of circular economy. 3D printing also has strong potential to act as an enabler through its intrinsic potential to alter the economics of the existing manufacturing value chain [13]. It is argued that low-cost, distributed 3D printing technology can help usher in a functional CE if guided by appropriate standards [9]. The following figure derived from van Wijk. \& van Wijk. (2015) gives a breakdown of ways 3D printing can contribute to the different aspects of Circular Economy [14]. 

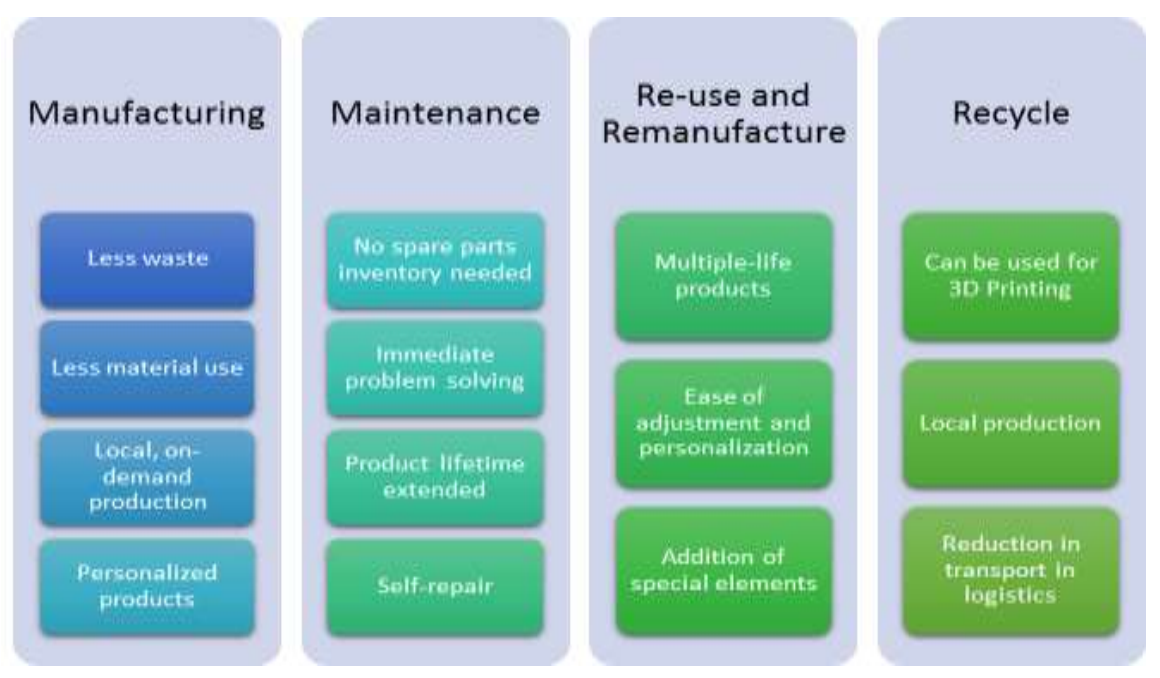

Figure 2: Contribution of 3D Printing to Circular Economy

(Derived from van Wijk. \& van Wijk. (2015))

As shown above, 3D printing can facilitate circularity at various stages; manufacturing, maintenance, reuse, re-manufacture and recycle. Each stage provides a unique yet essential opportunity to reduce wastage in terms of material, energy and cost. Various approaches are employed to maximize material utility, including reuse, repair, refurbishment, leasing, cascading, capacity sharing, or "dematerialization" [15]. A model developed by Unrun (2018) called the Biosphere Rules sought to establish a framework for implementing circular economy on a built additive manufacturing foundation. This framework is based on five principles modelled from observation of the cyclic, regenerative nature of the earth's natural systems: materials parsimony, value cycle, power autonomy, sustainable product platforms and function over form [9]. In order to encourage circularity, the right type of materials for $3 \mathrm{D}$ printing must be developed, biomaterials and bio-plastics in particular [14].

\subsection{Question 2 - What are the major challenges that inhibit the progression of CE in the additive manufacturing industry?}

The concept of Circular Economy pushes the frontiers of environmental sustainability; however, the widespread adoption of CE faces several barriers [3]. The issues and challenges discovered from the study can be classified into six (6) main categories: technical, organizational, economic, social, legislative and academic. These categories were determined through the nature of the issues that were discovered during the research procedure. A great level of interdependency exists between these categories, which affects the complexity of the issues addressed. Technical challenges include designing products for durability and ensuring upward compatibility, that is, making sure technologies utilized in the present would not be obsolete in the near future [16], and overlooked recycling details. Other issues surround the functional quality of 3D printing products [13] and toxicity of by-products [18]. Organizational issues such as restructuring material supply chains [12] and trade secrets and confidentialities [17] are multi-sectorial and therefore requires collaboration across companies, across even industries. It is possible for conflicts to arise from ill-defined roles and responsibilities and the perception that 3D printing is only for small-scale and not mass production [19]. The economic challenges identified were closely related to the organizational issues, as they were geared towards the high costing involved with the complexity of transforming participating sectors for re-manufacturing [3], significant up-front investments [20] and maintaining a consistent system of recycling. 
In terms of the social impact of the integration - more specifically for the circular economy - numerous articles have affirmed that it the aspect most overlooked. The extent to which a circular economy would impact subjective well-being [4], individual behaviour, consumerism and societal acceptance has not been thoroughly investigated by researchers. Other academic limitations include lack of research conducted in the feasibility of circular economy implementation [3] and lack of studies in the additive manufacturing domain. The legislative challenges vary according to the country, but those identified pertained to the need for laws and standardization of CE operations, and well-defined policies and procedures. Greater underlying issues include the ability of governments to enforce such laws [20], including sanctions for non-compliancy, illegal exportations and exploitations [15]. Academic challenges include lack of studies in examining the extent to which CE implementation strategies are feasible [3] and invisibility and intangibility of issues [21]. Lack of education and awareness are also key factors that inhibit the advancement of sustainability in manufacturing [12].

Besides those outlined within the six categories, there were other issues realised during the research on the integration. For example, it would be assumed that an ideology whose main aim is to regenerate the environment would not have any sufficient negative impact on said environment. However, studies suggest that circular economy might worsen the emission of greenhouse gases and, as a result, accelerate global warming [4]. This is due to the high energy levels required to power additive manufacturing equipment and global recycling systems, and the combined energy inefficiencies of these. In light of this, the influential actors in the circular economy and additive manufacturing integration must turn to renewable energy sources, which are still yet to be adopted by many industrial sectors. While movement towards circular economy has slowly gained traction in the last few years, the idea of circularity still remains foreign to many industries.

\section{Conclusion}

The integration of 3D printing sector with Circular Economy is a technological breakthrough which promises environmental and economic sustainability. Additive manufacturing has the potential to procure the facilitation of circularity by designing out waste, incorporating biomaterials and through allowing for design of maintenance and repair, and design for upgradability and recyclability. The journey to this facilitation, however, is a precarious one which encompasses a host of limitations and barriers to this integration. The findings presented suggest that the issues and challenges can be classified into six groups: technical, organizational, economic, social, legislative and academic. Each of these are complex and interdependent, and requires much research and active collaboration to overcome. The implementation of 3D printing technology with circular economy is also predominantly affected by the resistance brought about by the linear economy world order. It would be beneficial for further research to be pursued in the topic as the world's economies are slowly gearing toward more sustainable practices and as 3D printing technology becomes the new manufacturing norm. As more and more research, education and awareness arise, circular economy would slowly be integrated within the individual sectors, including that of the additive manufacturing industry, so that the global aim of environmental sustainability and regeneration can be attained.

\section{References}

[1] The Circle Economy Organization. 2018. The Circularity Gap Report 2018.

[2] The Circle Economy Organization. 2019. The Circularity Gap Report 2019. 
[3] O. Quelhas et al. 2018. Exploring Industry 4.0 technologies to enable circular economy practices in a manufacturing context: A Business Model Proposal. Journal of Manufacturing Technology Management. Emerald Publishing Limited.

[4] M. Geissdoerfer et al. 2017. The Circular Economy - A new sustainability paradigm? Journal of Cleaner Production. DOI: 10.1016/j.jclepro.2016.12.048

[5] O. Diegel et al. 2016. Additive Manufacturing and its Effect on Sustainable Design. Springer Science \& Business Media Singapore 2016 Handbook of Sustainability in Additive Manufacturing, Environmental Footprints and Eco-design of Products and Processes, DOI 10.1007/978-981-10-0549-7_5

[6] D. V. Betim et al. 2018. Analysis of the application of additive manufacturing in the circular economy: An integrative literature review. Operations Management for Social Good. POMS 2018. Springer Proceedings in Business and Economics.

[7] M. Sauerwein, C.A. Bakker, R.Balkenende. 2017. Additive Manufacturing for circular product design: A literature review from a design perspective. Delft University of Technology and IOS Press. DOI: 10.3233/978-1-61499-820-4-358.

[8] D. Giurco et al. 2014. Circular Economy: Questions for Responsible Minerals, Additive Manufacturing and Recycling of Metals. ISSN 2079-92763, 432-453; doi:10.3390/resources3020432.

[9] G. Unryh. 2018. Circular Economy, 3D Printing and the Biosphere Rules. California Management Review2018, Vol. 60(3) 95 -111. DOI: 10.1177/0008125618759684.

[10] Ellen MacArthur Foundation. What is the Circular Economy?

https://www.ellenmacarthurfoundation.org/circular-economy/what-is-the-circular-economy

[11] F.E. Garcia-Muiña et al. 2019. Identifying the Equilibrium Point between Sustainability Goals and Circular Economy Practices in an Industry 4.0 Manufacturing Context Using Eco-Design. Social Sciences ; Basel Vol. 8, Iss. 8.

[12] M. Despeisse, M. Baumers. 2016. Unlocking value for a circular economy through 3D printing. DOI: 10.13140/RG.2.1.4618.9685.

[13] A. Garmulewicz et al. 2018. Disruptive Technology as an Enabler of the Circular Economy: What Potential does 3D Printing Hold? California Management Review 2018, Vol. 60(3) 112 -132. DOI: $10.1177 / 0008125617752695$.

[14] A. van Wijk, I. van Wijk. 2015. 3D Printing with Biomaterials: Towards a Sustainable and Circular Economy (pg 73.) IOS Press.

[15] N. Kunz, K. Mayers, L. N. Van Wassenhove. 2018. Stakeholder Views on Extended Producer Responsibility and the Circular Economy. California Management Review2018, Vol. 60(3) 45 -70. DOI: $10.1177 / 0008125617752694$.

[16] P. Hopkinson et al. 2018. Managing a Complex Global Circular Economy Business Model: Opportunities and Challenges. California Management Review2018, Vol. 60(3) 71 -94. DOI: $10.1177 / 0008125618764692$.

[17] A.R. Zaoual. X. Lecocq. 2018. Orchestrating Circularity within Industrial Ecosystems: Lessons from Iconic Cases in Three different countries. California Management Review2018, Vol. 60(3) 133 -156. DOI: $10.1177 / 0008125617752693$

[18] D. Fratila, H. Rotaru. 2017. Additive manufacturing - A sustainable manufacturing route. MATEC Web of Conferences 94, 03004 DOI: 10.1051/ matecconf/2017940300494.

[19] M. Despeisse, S. Ford. 2015. The Role of Additive Manufacturing in Improving Resource Efficiency and Sustainability Centre for Technology Management working paper series. ISSN 2058-8887 No. 3

[20] D. Masi, S. Day, J. Godsell .2017. Supply Chain Configurations in the Circular Economy: A Systematic Literature Review. Doi:10.3390/su9091602.

[21] S. Prendeville et al. 2011. Makespaces: From Redistributed Manufacturing to a Circular Economy. Springer-Verlag Berlin Heidelberg. 